\title{
Stock Market Mean Reversion and the Optimal Equity Allocation of a Long-Lived Investor
}

\section{Citation}

Campbell, John Y., João Cocco, Francisco Gomes, Pascal J. Maenhout, and Luis M. Viceira. 2001. Stock market mean reversion and the optimal equity allocation of a long-lived investor. European Finance Review 5(3): 269-292.

\section{Published Version}

http://dx.doi.org/10.1023/A:1013860504885

\section{Permanent link}

http://nrs.harvard.edu/urn-3:HUL.InstRepos:3353758

\section{Terms of Use}

This article was downloaded from Harvard University's DASH repository, and is made available under the terms and conditions applicable to Other Posted Material, as set forth at http:// nrs.harvard.edu/urn-3:HUL.InstRepos:dash.current.terms-of-use\#LAA

\section{Share Your Story}

The Harvard community has made this article openly available.

Please share how this access benefits you. Submit a story.

\section{Accessibility}



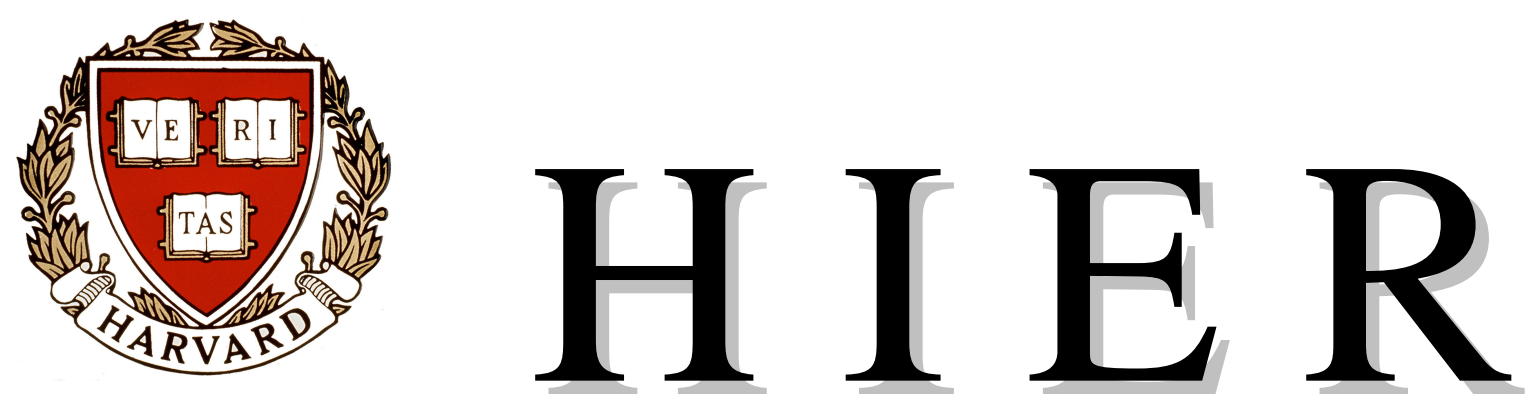

\title{
Harvard Institute of Economic Research
}

\author{
Discussion Paper Number 1899
}

\section{Stock Market Mean Reversion and the Optimal Equity Allocation of a Long-Lived Investor}

By

\section{John Y. Campbell, Joao Cocco, Francisco Gomes, Pascal Maenhout, and Luis Viceira}

\author{
June 2000 \\ Harvard University \\ Cambridge, Massachusetts
}

This paper can be downloaded without charge from the Social Science Research Network electronic library at: http://papers.ssrn.com/paper.taf?abstract_id=237175 


\title{
Stock Market Mean Reversion and the Optimal Equity Allocation of a Long-Lived Investor
}

\author{
John Y. Campbell, João Cocco, Francisco Gomes, \\ Pascal J. Maenhout and Luis M. Viceira ${ }^{1}$
}

First draft: September 1997

This version: May 2000

\footnotetext{
${ }^{1}$ Corresponding author: Prof. John Y. Campbell, Department of Economics, Littuaer Center 213, Harvard University, Cambridge MA 02138, and NBER. Tel 617-496-6448, email john_campbell@harvard.edu. Cocco and Gomes are at London Business School, Maenhout is at INSEAD, and Viceira is at Harvard Business School. We gratefully acknowledge the financial support of the National Science Foundation (Campbell), the Banco de Portugal (Cocco), Fundacão para a Ciencia e Tecnologia (Cocco and Gomes), the Fund for Scientific Research Flanders (Maenhout), and the Bank of Spain (Viceira).
} 


\begin{abstract}
This paper solves numerically the intertemporal consumption and portfolio choice problem of an infinitely-lived investor who faces a time-varying equity premium. The solutions we obtain are very similar to the approximate analytical solutions of Campbell and Viceira (1999), except at the upper extreme of the state space where both the numerical consumption and portfolio rules flatten out. We also consider a constrained version of the problem in which the investor faces borrowing and short-sales constraints. These constraints bind when the equity premium moves away from its mean in either direction, and are particularly severe for risk-tolerant investors. The optimal constrained portfolio rules are similar but not identical to the optimal unconstrained rules with the constraints imposed. The portfolio constraints also affect the optimal consumption policy.
\end{abstract}

JEL classification: G12.

Keywords: Hedging demand, intertemporal portfolio choice, mean reversion. 


\section{Introduction}

This paper solves numerically the intertemporal consumption and portfolio choice problem of an infinitely-lived investor who faces a time-varying equity premium. There is now considerable evidence that the excess return on stocks over Treasury bills is predictable (see Campbell 1987, Campbell and Shiller 1988, Fama and French 1988, 1989, Hodrick 1992, or the textbook treatment in Campbell, Lo, and MacKinlay 1997, Chapter 7). Merton (1969, 1971), Samuelson (1969), and Giovannini and Weil (1989) have shown that time variation in investment opportunities affects portfolio choice unless investors have unit relative risk aversion. But the large literature on the equity premium puzzle finds that average excess stock returns are too high to be consistent with a representative-investor model with unit relative risk aversion (see Campbell 1996, Cecchetti, Lam, and Mark 1994, Cochrane and Hansen 1992, Hansen and Jagannathan 1991, Kocherlakota 1996, Mehra and Prescott 1985, or the textbook treatment in Campbell, Lo, and MacKinlay 1997, Chapter 8). Therefore, it is important to analyze optimal consumption and portfolio decisions when there is time variation in the investment opportunity set and investors have risk aversion different from one.

The problem, however, is not trivial analytically. Nonlinearities in both the Euler equations and the intertemporal budget constraint make it extremely hard to find exact analytical solutions. Recently a few special cases have been solved. In a continuous-time model with a constant riskless interest rate and a single risky asset whose expected return follows a mean-reverting AR(1) process, for example, the model can be solved if long-lived investors have power utility defined over terminal wealth (Kim and Omberg 1996), or if investors have power utility defined over consumption and the innovation to the expected asset return is perfectly correlated with the innovation to the unexpected return, making the asset market effectively complete (Wachter 1999), or if the investor has Epstein-Zin utility with intertemporal elasticity of substitution restricted to equal one (Campbell and Viceira 1999, Schroder and Skiadas 1999).

We use a numerical solution method that allows us to consider a somewhat more general discrete-time model than any of these special cases. We assume a constant riskless interest rate and an $\mathrm{AR}(1)$ process for the risky asset return, but we do not assume perfect correlation between innovations to the expected and unexpected return, and we allow the investor to have general Epstein-Zin utility defined over consumption. We begin by discretizing the state-space and approximating the distribution

for the innovations in the random variables using Gaussian quadrature. The solution algorithm assumes a portfolio allocation rule which is a $p$ th order polynomial in the 
state-variable and uses a variant of the Newton-Raphson algorithm to optimize over the coefficients of this polynomial. We use the Den Haan-Marcet (DHM) statistic (Den Haan and Marcet 1994) to choose the optimal value for $p$, and to evaluate the accuracy of the numerical solution. We find that the portfolio rule is approximately linear in the state variable while the log consumption-wealth ratio is approximately quadratic. These approximations break-down as the state variable deviates substantially from its unconditional mean.

Our use of Epstein-Zin preferences (Epstein and Zin (1989), Weil (1990)) allows us to consider different combinations of risk aversion and the elasticity of intertemporal substitution in consumption. We find that the importance of hedging demand for portfolio choice depends strongly on risk aversion, but hardly at all on the elasticity of intertemporal substitution.

We also consider a constrained version of the problem in which the investor is not allowed to borrow at the riskless interest rate or to short-sell the risky asset. Such constraints are realistic, and they affect the form of the solution since the investor's optimal plans take account of the possibility that the constraints may bind in the future, even if they are not binding today. We find that, in the region in which they are not binding, these constraints have a large impact on the consumption rule but little effect on the portfolio rule.

Campbell and Viceira (1999, henceforth CV) derive an approximate analytical solution for the unconstrained version of this problem, by log-linearizing the Euler equations and the intertemporal budget constraint. This approximate analytical approach yields portfolio and consumption rules that are, respectively, linear and quadratic in the single state variable of the problem. The numerical solutions we obtain are similar to the approximate analytical solutions of CV, except at the upper extreme of the state space where both the numerical portfolio and consumption rules flatten out. We also use the DHM statistic to test the accuracy of the log-linear solution in CV.

This paper extends the results in Campbell and Koo (1997, henceforth CK). CK take the agent's portfolio at each point in time as given and assume a time-series process for the return on this portfolio. They solve numerically for the optimal allocation of the investor's wealth between consumption and savings. Here we solve numerically for the investor's optimal portfolio as well. This allows us to assess the accuracy of log-linear approximations in problems involving both portfolio and consumption choice.

A number of other recent papers have also presented numerical solutions to intertemporal consumption and portfolio choice problems. Important examples include Balduzzi and Lynch (1999), Barberis (2000), Brandt (1999), Brennan, Schwartz, 
and Lagnado (1996, 1997), Cocco, Gomes, and Maenhout (1998), and Lynch (1999). These papers concentrate on problems with a finite horizon and power utility, typically defined over wealth, whereas we consider an infinite horizon and Epstein-Zin utility over consumption. Our paper also differs in its careful comparison of analytical and numerical solutions, and of constrained and unconstrained solutions.

The structure of the paper is as follows. In section 2 we present the problem we would like to solve, following CV. Section 3 describes the solution algorithm as well as the DHM test used to evaluate its accuracy. In Section 4 we present and discuss the numerical solutions for the unconstrained and constrained optimization problems. Section 5 concludes.

\section{The model}

We consider an infinitely-lived investor with recursive preferences described by:

$$
U\left(C_{t}, \mathrm{E}_{t} U_{t+1}\right)=\left\{(1-\delta) C_{t}^{1-\frac{1}{\psi}}+\delta\left(\mathrm{E}_{t} U_{t+1}^{1-\gamma}\right)^{\frac{1-\frac{1}{\psi}}{1-\gamma}}\right\}^{\frac{1}{1-\frac{1}{\psi}}}
$$

where $C_{t}$ is the investor's period $t$ consumption, $\delta<1$ is the discount factor, $\gamma>0$ is the coefficient of relative risk aversion and $\psi>0$ is the elasticity of intertemporal substitution. These preferences were proposed by Epstein and Zin (1989) and Weil (1990) as a generalization of power utility that disentangles risk aversion from the elasticity of intertemporal substitution. Power utility is the special case where $\psi=$ $1 / \gamma$.

Each period the investor must decide how much to consume out of her wealth and how to allocate the remaining wealth between two tradable assets: A risky asset (asset 1) with one-period log return given by $r_{1, t+1}$ and a riskless asset (asset $f$ ) with constant log return given by $r_{f}$.

The model assumes that the expectation of the log excess return $\left(r_{1, t+1}-r_{f}\right)$ on the risky asset is state-dependent,

$$
\mathrm{E}_{t}\left[r_{1, t+1}-\bar{r}_{f}\right]=x_{t},
$$

where $x_{t}$ is the single state variable of the model that follows an $\operatorname{AR}(1)$ process:

$$
x_{t+1}=\mu+\phi\left(x_{t}-\mu\right)+\eta_{t+1} .
$$

The unexpected log excess return is denoted by $u_{t+1}$. The random variables $u_{t+1}$ and $\eta_{t+1}$ are jointly normal and conditionally homoskedastic, with variances $\sigma_{u}^{2}$ and $\sigma_{\eta}^{2}$, 
respectively. We also allow for correlation between the unexpected log excess return and innovations in the state variable, and denote their covariance by $\sigma_{u \eta}$.

So far the setup is very similar to the one in CK. They however take the rate of return on the portfolio as given, whereas we consider the investor's optimal portfolio as well and thus introduce an additional choice variable. The one-period return on the portfolio from time $t$ to time $t+1$ is

$$
R_{p, t+1}=\alpha_{t}\left(R_{1, t+1}-R_{f}\right)+R_{f}
$$

where $R_{1, t+1}=\exp \left\{r_{1, t+1}\right\}, R_{f}=\exp \left\{r_{f}\right\}$ and $\alpha_{t}$ is the proportion of total wealth invested in the risky asset at time $t$.

We want to solve for the intertemporal consumption and portfolio policies that maximize (1) subject to the budget constraint

$$
W_{t+1}=R_{p, t+1}\left(W_{t}-C_{t}\right),
$$

where $W_{t}$ is total wealth at the beginning of time $\mathrm{t}$ and $R_{p, t+1}$ is the return on wealth (4).

The investor's objective function (1) has been normalized so that the value function is homogeneous of degree one. Therefore, we can solve for the optimal consumptionwealth ratio and portfolio allocation rule when the investor has wealth equal to one. Following CK we simplify notation by defining $x \equiv x_{t}, y \equiv x_{t+1}, R_{1} \equiv R_{1, t+1}$ and $R_{p} \equiv R_{p, t+1}$. We also denote the unit wealth indirect value function by $V(x)$, the consumption-wealth ratio by $c(x)$, and the fraction of wealth invested in the risky asset by $\alpha(x)$. The problem we solve is:

$$
V(x)=\max _{0 \leq c(x) \leq 1, \alpha(x)}\left\{(1-\delta) c(x)^{1-\frac{1}{\psi}}+\delta(1-c(x))^{1-\frac{1}{\psi}}\left\{\mathrm{E}\left[V(y)^{1-\gamma} R_{p}^{1-\gamma} \mid x\right]\right\}^{\frac{1-\frac{1}{\psi}}{1-\gamma}}\right\}^{\frac{1}{1-\frac{1}{\psi}}}
$$

Epstein and Zin (1989) show that the Euler equations for consumption and portfolio choice for this problem are given by

$$
c(x)=\frac{C}{1+C}
$$

where

$$
\begin{gathered}
C=\left(\frac{1-\delta}{\delta}\right)^{\psi}\left\{\mathrm{E}\left[V(y)^{1-\gamma} R_{p}^{1-\gamma} \mid x\right]\right\}^{\frac{1-\psi}{1-\gamma}}, \\
\mathrm{E}\left[V(y)^{1-\gamma} R_{p}^{-\gamma}\left(R_{1}-\bar{R}_{f}\right) \mid x\right]=0
\end{gathered}
$$


and

$$
R_{p}=\alpha(x)\left(R_{1}-R_{f}\right)+R_{f}
$$

Unfortunately, it is not possible to write $\alpha(x)$ explicitly as a function of $V(y)$ and $c(x)$. Therefore a fully numerical solution to this problem would involve solving the non-linear equation (8) for $\alpha(x)$. Instead we assume that $\alpha(x)$ is a $p$ 'th order polynomial in the state-variable:

$$
\alpha(x)=a_{0}+a_{1} x+a_{2} x^{2}+\ldots+a_{p} x^{p}
$$

and optimize with respect to the coefficients of the polynomial. The approximate analytical solution proposed by CV is a particular case of (10), with $a_{j}=0$ for $j \geq 2$.

\section{Numerical solution}

\subsection{Parameter values}

We calibrate the model using postwar US financial data at a quarterly frequency. In the calibration exercise the risky asset is the aggregate stock market and the riskless asset is a short-term debt instrument. The single state variable of the problem is the $\log$ dividend-price ratio, $\left(d_{t}-p_{t}\right)$. We obtain the parameters that define the stochastic structure of the model from CV's estimates of the following restricted VAR(1) model

$$
\left(\begin{array}{c}
r_{1, t+1}-r_{f} \\
d_{t+1}-p_{t+1}
\end{array}\right)=\left(\begin{array}{c}
\theta_{0} \\
\beta_{0}
\end{array}\right)+\left(\begin{array}{c}
\theta_{1} \\
\beta_{1}
\end{array}\right)\left(d_{t}-p_{t}\right)+\left(\begin{array}{c}
\varepsilon_{1, t+1} \\
\varepsilon_{2, t+1}
\end{array}\right),
$$

where $\left(\varepsilon_{1, t+1}, \varepsilon_{2, t+1}\right) \sim N(0, \Omega)$. CV show how to solve for the parameters of the theoretical model given the estimated parameters of (11). Table 1 reports both sets of parameters.

The discount factor under time-additive utility $\delta$ is set to 0.94 in annual terms. We solve the model for coefficients of relative risk aversion $\gamma$ of $1,2,4,10$, and 20 , and for elasticities of intertemporal substitution $\psi$ of $1,0.5,0.25,0.1$, and 0.05 . Each of these values is the reciprocal of one of our risk aversion values, so we consider the power utility cases for which $\psi=1 / \gamma$. We emphasize values for $\psi \leq 1$ since time-series studies of representative-agent models suggest that $\psi$ is well below one and may be close to zero (Hall 1988, Campbell and Mankiw 1989). 


\subsection{Solution algorithm}

We discretize the state space and approximate it with 35 equally spaced grid points, centered at the unconditional mean of the state variable. We set the distance between any two points to $0.25 \%$. We approximate the distribution for the innovations to the state variable using Gaussian quadrature methods with 9 quadrature points.

We use the Newton-Raphson algorithm to optimize over the coefficients of the policy function for $\alpha(x)$, allowing for either a third or a fourth order polynomial in the state variable. The approximate analytical solution in CV involves a portfolio allocation rule which is linear in the state-variable. Since the log-linear solution is likely to be close to the optimal solution we use its coefficients as our initial values, with the coefficients in the higher order terms initialized at zero. This makes divergence of our numerical algorithm less likely and reduces the time needed to obtain convergence.

We initialize the value function by setting it equal to a constant. The results obtained are not sensitive to the value of this constant in a wide range around the mean value implied by the CV log-linear solution.

The solution algorithm consists of the following stages:

1. Given initial values for the coefficients of the portfolio rule (10) and for the value function, we compute the consumption rule using equation (7).

2. We use this consumption rule to compute a new value function using equation (6). We iterate on this functional equation until the value function converges at each state.

3. We repeat stages 1 and 2 , still fixing the portfolio rule, until convergence. This gives us a consumption rule and value function that correspond to the parameters of the portfolio rule.

4. We evaluate numerically the gradient $(G)$ of the value function at each state with respect to the coefficients of $\alpha(x)$ as follows. Using stages 1-3 we compute the consumption rule and value function corresponding to perturbed coefficients. Given these values we compute the gradient for each state. In order to determine the direction of steepest ascent we compute a weighted average of these gradients using the ergodic probability distribution of the state variable.

5. To determine the optimal step size we compute the Hessian $(H)$ of the value function with respect to the coefficients, using the same approach as in stage 4 . 
To avoid divergence problems we reduce the step size, setting new coefficients equal to

$$
\alpha_{k+1}=\alpha_{k}-\lambda H^{-1} G,
$$

where $k$ refers to the iteration, and $\lambda$ is set initially to $2 / 3$. Given these coefficients the new weighted average value function is compared with the previous one and if there is no improvement $\lambda$ is reduced (multiplied by 2/3). This is repeated until the weighted average value function increases.

6. We use the coefficients obtained in stage 5 to compute a new consumption rule and value function as in stages 1-3. Given the new consumption rule and value function we repeat stages 4-5. We iterate this process until the weighted average value function converges.

For some parameter values the exact analytical solution is known for part of the problem (Giovannini and Weil 1989). In particular, when $\psi=1$ one obtains a myopic optimal consumption rule in which the investor consumes in each period a fixed fraction of his wealth. On the other hand, when $\gamma=1$ one obtains the same myopic optimal portfolio allocation rule as with log utility. For these special cases we changed our numerical algorithm by imposing the known exact analytical solution for the consumption and portfolio rules, respectively.

\subsection{Accuracy of the solution}

To test the accuracy of the numerical solution we use the Den Haan-Marcet (DHM) statistic (Den Haan and Marcet 1994). The DHM statistic does not require knowledge of the true solution and it can be used to select between different functional forms for the policy functions. We based our choice between a third and a fourth order polynomial for $\alpha(x)$ on the values obtained for the DHM statistics.

In order to implement this test we first simulate different time series of realizations for the exogenous variables, $u$ and $\eta$. Given these realizations and the optimal numerical consumption and portfolio allocation rules, we compute the expectational errors $\left(\varepsilon_{t+1}\right)$ implied by the Euler equations of the model, (7) and (8). These expectational errors should be orthogonal to the previous period's information set:

$$
\mathrm{E}\left[\varepsilon_{t+1} \otimes h\left(z_{t}\right)\right]=0,
$$

for any function $h($.$) and any variable z_{t}$ belonging to the information set available at time t. In our application we choose a vector of instruments $z_{t}=\left(1, x_{t}, x_{t}^{2}\right)$, and set $h($.$) equal to the identity function.$ 
Given these instruments we can test the accuracy of our numerical solution by computing:

$$
B_{t} \equiv \frac{\sum_{t=1}^{T} \varepsilon_{t+1} \otimes h\left(z_{t}\right)}{T},
$$

and testing whether $B_{T}$ is statistically different from zero. The significance of deviations from zero is evaluated by using the DHM test statistic

$$
T B_{T}^{\prime} A_{T}^{-1} B_{T},
$$

where

$$
A_{T} \equiv \frac{\sum_{t=1}^{T}\left[\varepsilon_{t+1} \otimes h\left(z_{t}\right)\right]\left[\varepsilon_{t+1} \otimes h\left(z_{t}\right)\right]^{\prime}}{T} .
$$

Under the null hypothesis that the numerical solution is correct the asymptotic distribution (as $T \rightarrow \infty$ ) of this test statistic is a $\chi_{q m}^{2}$ where $m$ is the number of Euler equations being tested (two in the general case and one in the special cases where part of the solution is known) and $q$ is the dimension of $h$ (three in our application with three instruments where $h$ is the identity function).

By comparing the result of (14) with the relevant critical values we can obtain evidence on the validity of the numerical solution. In order to reduce (and in the limit eliminate) the possibility of type I errors we performed a large number of simulations and computed the percentage of test results in the upper and lower $5 \%$ critical values of a $\chi_{q m}^{2}$. In particular, we used 2000 time-series of 400 observations each, giving us 100 years of data as in CK (1997).

\section{Numerical results}

\subsection{Unconstrained problem}

In this section we present our numerical results for the unconstrained problem in which the investor can short-sell either of the assets. We report results when the portfolio allocation rule is modelled as a third-order polynomial in the state variable. We choose a third-order polynomial because convergence for a fourth-order polynomial is much slower while the DHM statistics are little better than for a third-order polynomial.

Figures 1a and 2a plot the optimal portfolio rule as a function of the state variable. For comparison purposes the log-linear (CV) solution is also included. Figure 1a plots the portfolio allocation rules for $\gamma=4$ and 20 and $\psi=1 / .75$, while Figure 2a plots those rules for the same coefficients of relative risk aversion and $\psi=1 / 4$. The solid vertical lines in the figures are drawn two standard deviations above and below 
the unconditional mean of the state variable. These figures show that the log-linear solution and the numerical solution are very close in a large interval around the mean of the state-space, where both rules are approximately linear with almost exactly the same level and slope. However the numerical solution flattens out towards the upper extreme of the state-space.

Figures $2 \mathrm{a}$ and $2 \mathrm{~b}$ plot the optimal consumption-wealth ratio as a function of the state variable, using the same preference parameters as Figures 1a and 1b. Again the solution in $\mathrm{CV}$ is also reported for comparison. Instead of postulating a functional form for the numerical optimal consumption rule, we used (7) to obtain it; thus the only approximations involved in our solution method are the discretization of the state-space, the 9-point Gaussian quadrature approximation of the distribution of the random variables, and the restriction of the functional form for $\alpha(x)$. Again, the optimal numerical and log-linear consumption rules are very close in most of the state-space, except at the upper extreme, where the numerical solution flattens out.

It is interesting to note that the optimal numerical and log-linear rules tend to be closer over a larger portion of the state space when the coefficient of relative risk aversion is large than when it is small. One might have thought that the greater curvature of the utility function implied by large risk aversion would negatively affect the accuracy of the approximation; but in this model greater curvature actually helps the approximation because it limits the extent to which the investor wants to take advantage of the predictability in excess returns.

Table 2 presents the mean optimal numerical percentage allocation to stocks and the optimal numerical and log-linear percentage allocation to stocks at the mean of the state-space. The difference between these two values is the result of Jensen's inequality; there is no difference in the approximate solution, since it is linear in the state variable. For $\gamma=1$ portfolio choice is myopic, and therefore the log-linear and numerical results coincide (and do not depend on $\psi$ ). In general, the average optimal allocation to stocks varies significantly with $\gamma$, but little with $\psi$, a pattern already identified by $\mathrm{CV}$.

We do not present results for $\gamma<1$ because in this region of the parameter space we encounter difficult numerical convergence problems. The value function tends to increase without limit at the extremes of the state space, because the investor's low risk aversion combined with a high and time-varying equity premium lead the individual to aggressively time the stock market and achieve very high or even unbounded utility. One way to assist convergence is to consider a lower $\delta$, but even with this shift in parameters the DHM statistics indicate that the numerical solution is not very accurate.

In Table 2 we see that the mean optimal log-linear percentage allocation to stocks 
is slightly larger than the one obtained numerically. This is due to the fact that the numerical optimal portfolio allocation rule flattens out towards the upper extreme of the state-space whereas the approximate analytical rule keeps on increasing linearly. However, this happens mostly for values of the state-variable for which the unconditional probability is very small, and therefore the mean optimal log-linear and numerical allocations are very close.

Table 3 reports the standard deviations of the optimal numerical and log-linear portfolio rules. The fact that the optimal numerical portfolio rule is approximately linear around the unconditional mean of the state-variable but flattens out towards the upper extreme of the state-space, whereas the log-linear portfolio rule is linear throughout, explains why the latter has a higher standard deviation. Again, the difference between the two standard deviations is small because of the low unconditional probability of the portion of the state space where the flattening occurs. The standard deviation of the optimal percentage allocation to stocks decreases with $\gamma$ since risk-averse individuals are less aggressive market timers.

Tables 4 through 6 present analogous calculations for the consumption-wealth ratio. In interpreting these tables one should remember that the optimal log-linear consumption policy is quadratic in the state-variable. This is why the optimal loglinear percentage consumption-wealth ratio at the mean of the state-space and the mean optimal log-linear consumption wealth ratio do not coincide. Also, for $\psi=1$ the exact analytical consumption-wealth ratio is known and therefore the log-linear and numerical solutions coincide (and do not depend on $\gamma$ ).

The sensitivity of the consumption-wealth ratio to the parameters $\gamma$ and $\psi$ is similar for the log-linear and numerical solutions. For values of $\psi<1(>1)$ the mean optimal percentage consumption-wealth ratio is increasing (decreasing) in $\gamma$. For low (high) values of $\gamma$ the mean optimal percentage consumption-wealth ratio is increasing (decreasing) in $\psi$. The intuition is the same as in CV. Highly risk-averse investors, at the bottom of the table, hold most of their wealth in the riskless asset and hence earn a low return. If this return is below the rate of time preference, investors that are unwilling to substitute consumption intertemporally $(\psi<1)$ choose to consume more out of wealth than investors who are willing to substitute consumption intertemporally $(\psi>1)$. The income effect of a negative time-preference-adjusted rate of return on saving dominates for investors with $\psi<1$, while the substitution effect dominates for investors with $\psi>1$. This pattern reverses for risk-tolerant investors, in the upper part of the table, because these investors hold risky portfolios whose expected rate of return is larger than their rate of time preference.

Table 6 presents the standard deviations of the optimal log-linear and numerical consumption-wealth ratios. In general the log-linear standard deviations are larger. 
The reason is that our numerical policy functions are approximately quadratic at the unconditional mean of the state-space (and very similar to the log-linear policy functions) but flatten out towards the upper extreme of the state-space as shown in Figures $1 \mathrm{~b}$ and $2 \mathrm{~b}$. This pattern is similar to the one we obtained for the portfolio rule in Table 3.

Table 7 presents DHM tests of the accuracy of our numerical solutions. If our solutions were exact, the DHM statistics would give us $5 \%$ of errors in both the lower and upper critical tails. The numbers reported in Table 7 lie between $2 \%$ and $10 \%$ and generally cluster around 5\%, implying that our numerical solutions are quite accurate. CK obtained better DHM test results, but their model has only one decision variable and one Euler equation. We note that we also obtain DHM statistics closer to 5\% in the special cases $(\gamma=1$ or $\psi=1)$ for which we have only one decision variable.

We also used DHM statistics to evaluate the accuracy of the log-linear (CV) solution. In order to do this we calculated numerically the value function implied by the log-linear portfolio and consumption rules, using stage 2 of our numerical algorithm. The log-linear solution dramatically fails the DHM test, giving 0\% of errors in the lower tail and $100 \%$ of errors in the upper tail. Evidently the inaccuracy at the upper extreme of the state space, shown in Figures 1 and 2, has a large impact on the DHM statistics. These findings also illustrate the power of DHM statistics to detect small deviations from the optimal solution.

Finally, we use DHM statistics to explore the importance of nonlinearities in the portfolio rule. We compare the DHM statistics for numerical solutions based on the third-order polynomial portfolio rule, a second-order polynomial rule, a first-order polynomial rule, and a first-order rule restricted to have the slope implied by the loglinear CV solution. In each case we calculate the optimal consumption rule and value function using our standard numerical algorithm. The results are not reported in a table, but can be summarized as follows. For low coefficients of relative risk aversion such as $\gamma=2$, there is a modest deterioration in DHM statistics from about $7 \%$ to about $10 \%$ as one reduces the order of the portfolio polynomial and restricts its slope to the $\mathrm{CV}$ value. For high coefficients of risk aversion such as $\gamma=10$, there is again a modest deterioration in DHM statistics to about $10 \%$ as one reduces the order of the portfolio polynomial, but a larger deterioration when the slope is restricted to the $\mathrm{CV}$ value.

\subsection{Constrained problem}

In this section we present numerical results for the constrained problem in which the investor is not allowed to borrow at the riskfree rate or to short-sell the risky asset, 
so the portfolio share $\alpha(x)$ is constrained to lie in the unit interval. Our main focus in this section is to compare the constrained and unconstrained numerical solutions.

Our solution algorithm for the constrained problem is a slight variation of the one presented above for the unconstrained problem. At each iteration of the algorithm the portfolio allocation rule is given by:

$$
\alpha_{k}^{\text {const }}(x)=\operatorname{Min}\left[\operatorname{Max}\left(a_{0}^{k}+a_{1}^{k} x+a_{2}^{k} x^{2}+a_{3}^{k} x^{3}, 0\right), 1\right]
$$

where $k$ refers to the iteration. The results for the constrained problem are presented in Tables 8 and 9. Figures 3 and 4 plot the constrained and unconstrained optimal portfolio and consumption rules for $\gamma=4$ and 20 and $\psi=1 / 4$.

The constrained portfolio rules, like the unconstrained rules, are nondecreasing in the state variable. Thus the zero constraint binds when the state variable is low, and the unit constraint binds when the state variable is high. This means that if the constrained model is a reasonable approximation to reality investors should be out of the stock market at a time when the log dividend-price ratio is low. Figure 3 illustrates that the area over which the portfolio rules are constrained decreases as the coefficient of relative risk aversion increases. This is of course a consequence of the fact that risk-averse investors have lower average stock allocations and are less aggressive market timers. The figure also shows that the slope of the optimal rule in the unconstrained region may be affected by the existence of the constrained region; nonetheless the unconstrained solution, with the constraints imposed, appears to be a good first approximation to the constrained solution.

The presence of binding constraints implies that the standard deviation of the optimal constrained percentage allocation to stocks (Table 8) is smaller than the standard deviation of the unconstrained allocation (Table 3). The constraints reduce the average allocation to stocks for investors with low coefficients of risk aversion, since these investors more often wish to leverage their stockholdings than to sell stocks short; but the constraints increase the average allocation for highly risk-averse investors, who more often wish to sell short than to leverage their stockholdings.

The portfolio constraints also affect the consumption-investment decision. For example, when the state variable is sufficiently low the investor would like to short the risky asset, which he is not allowed to do. Instead he holds the riskless asset, and earns a smaller return than he would otherwise. This affects the steady-state value of his consumption-wealth ratio. Comparing Tables 5 and 8 we see that for $\psi<1$ the mean optimal percentage consumption-wealth ratio with constrained portfolio choice is smaller than the one with unconstrained portfolio choice. This result can be understood by considering the income and substitution effects of portfolio constraints. 
Portfolio constraints reduce the average portfolio return, which reduces consumption through the income effect but increases consumption through the substitution effect. When $\psi<1$ the income effect dominates, but when $\psi>1$ the substitution effect dominates and the portfolio constraints increase average consumption.

Comparing Tables 6 and 9 we see that portfolio constraints reduce the standard deviation of the optimal consumption-wealth ratio. An intuitive way of understanding this result is to note that portfolio constraints make the several states look more alike. For example, even if the log dividend-price ratio is very high, the investor is limited in his ability to exploit this unusual investment opportunity. This effect is stronger for investors with low risk aversion, who are constrained over a larger region of the state space.

\section{Conclusion}

This paper has analyzed the implications of stock return predictability for the portfolio and consumption decisions of long-lived investors. We have studied investors who consume out of their financial wealth and have recursive Epstein-Zin-Weil utility, a generalization of power utility that enables us to distinguish between the coefficient of relative risk aversion and the elasticity of intertemporal substitution. We assume that these investors choose in discrete time between a riskless asset with a constant return, and a risky asset with constant return variance whose expected log return follows an $\mathrm{AR}(1)$ process. We have calibrated the asset return processes to fit the behavior of postwar US stock returns, using the log dividend-price ratio as a proxy for the expected log stock return.

We have used numerical techniques to obtain the optimal policies. We find that the optimal portfolio rule is approximately linear and the log consumption-wealth ratio approximately quadratic in the state variable over a wide interval around the unconditional mean of the state variable. However, both policy functions flatten out towards the upper extreme of the state space. The investor responds less aggressively to movements in the log dividend-price ratio when the ratio is already extremely high.

We have also calculated the optimal policies for investors who face borrowing and short-sales constraints. This is probably a more realistic problem for many investors. We find that the constrained optimal portfolio rules are close to the unconstrained optimal rules with constraints imposed, and are particularly close for investors with high risk aversion. The presence of constraints has important effects on both the level and variability of optimal consumption.

We have compared our numerical solution with the approximate analytical solu- 
tion proposed by Campbell and Viceira (1999), in which the portfolio rule is globally linear and the consumption rule is globally quadratic. For the parameter values considered here, the approximate analytical solution is very close to the numerical solution provided that the state variable is no more than two standard deviations above its mean. However the analytical solution cannot capture the flattening out of the policy functions at high values of the state variable.

Den Haan-Marcet (1994) statistics are sensitive indicators of errors in candidate solutions to dynamic optimization problems. These statistics indicate that our numerical solution is quite accurate, but they are able to pick up the approximation errors in the analytical solution at the upper end of the state space.

\section{References}

Balduzzi, Perluigi and Anthony Lynch, 1999, "Transaction Costs and Predictability: Some Utility Cost Calculations", Journal of Financial Economics 52, 47-78.

Barberis, Nicholas C., 2000, "Investing for the Long Run When Returns Are Predictable", Journal of Finance 55, 225-264.

Brandt, Michael, 1999, "Estimating Portfolio and Consumption Choice: A Conditional Euler Equations Approach", Journal of Finance 54, 1609-1645.

Brennan, Michael J., Eduardo S. Schwartz, and Ronald Lagnado, 1996, "The Use of Treasury Bill Futures in Strategic Asset Allocation Programs", Finance Working Paper 7-96, Anderson Graduate School of Management, UCLA, Los Angeles, CA.

Brennan, Michael J., Eduardo S. Schwartz, and Ronald Lagnado, 1997, "Strategic Asset Allocation", Journal of Economic Dynamics and Control 21, 1377-1403.

Campbell, John Y., 1987, "Stock Returns and the Term Structure", Journal of Financial Economics 18, 373-399.

Campbell, John Y., 1996, "Understanding Risk and Return", Journal of Political Economy 104, 298-345.

Campbell, John Y. and Hyeng Keun Koo, 1997, "A Comparison of Numerical and Analytical Approximate Solutions to an Intertemporal Consumption Choice Problem", Journal of Economic Dynamics and Control 21, 273-295. 
Campbell, John Y., Andrew W. Lo and A. Craig MacKinlay, 1997, The Econometrics of Financial Markets, Princeton University Press, Princeton, NJ.

Campbell, John Y. and N. Gregory Mankiw, 1989, "Consumption, Income, and Interest Rates: Reinterpreting the Time-Series Evidence," in NBER Macroeconomics Annual 1989, MIT Press, Cambridge, MA.

Campbell, John Y. and Robert Shiller, 1988, "The Dividend-Price Ratio and Expectations of Future Dividends and Discount Factors", Review of Financial Studies $1,195-227$.

Campbell, John Y. and Luis M. Viceira, 1999, "Consumption and Portfolio Decisions when Expected Returns are Time Varying", Quarterly Journal of Economics 114, 433-495.

Cecchetti, Steven, Pok-sang Lam and Nelson C. Mark, 1994, "Testing Volatility Restrictions on Intertemporal Marginal Rates of Substitution Implied by Euler Equations and Asset Returns", Journal of Finance 49, 123-152.

Cocco, Joao, Francisco Gomes, and Pascal Maenhout, 1998, "Consumption and Portfolio Choice over the Life Cycle", unpublished paper, Harvard University.

Cochrane, John and Lars P. Hansen, 1992, "Asset Pricing Explorations for Macroeconomics", in NBER Macroeconomics Annual 1992, Massachusetts Institute of Technology Press, Cambridge, MA, 115-165.

Den Haan, Wouter J. and Albert Marcet, 1994, "Accuracy in Simulations", Review of Economic Studies 61, 3-17.

Epstein, Lawrence and Stanley Zin, 1989, "Substitution, Risk Aversion, and the Temporal Behavior of Consumption and Asset Returns: A Theoretical Framework", Econometrica 57, 937-69.

Fama, Eugene and Kenneth French, 1988, "Dividend Yields and Expected Stock Returns", Journal of Financial Economics 22, 3-27.

Fama, Eugene and Kenneth French, 1989, "Business Conditions and Expected Returns on Stocks and Bonds", Journal of Financial Economics 25, 23-49.

Giovannini, Alberto and Philippe Weil, 1989, "Risk Aversion and Intertemporal Substitution in the Capital Asset Pricing Model", NBER Working Paper No. 2824 . 
Hall, Robert E., 1988, "Intertemporal Substitution in Consumption," Journal of Political Economy 96, 339-357.

Hansen, Lars P. and Ravi Jagannathan, 1991, "Restrictions on Intertemporal Marginal Rates of Substitution Implied by Asset Returns", Journal of Political Economy 99, 225-262.

Hodrick, Robert J., 1992, "Dividend Yields and Expected Stock Returns: Alternative Procedures for Inference and Measurement", Review of Financial Studies $5,357-386$.

Kim, Tong Suk and Edward Omberg, 1996, "Dynamic Nonmyopic Portfolio Behavior", Review of Financial Studies 9, 141-161.

Kocherlakota, Narayana R., 1996, "The Equity Premium: It's Still a Puzzle", Journal of Economic Literature 34, 42-71.

Lynch, Anthony W., 1999, "Portfolio Choice and Equity Characteristics: Characterizing the Hedging Demands Induced by Return Predictability", unpublished paper, New York University.

Mehra, Rajnish and Edward C. Prescott, 1985, "The Equity Premium: A Puzzle", Journal of Monetary Economics 15, 145-161.

Merton, Robert C., 1969, "Lifetime Portfolio Selection Under Uncertainty: The Continuous Time Case", Review of Economics and Statistics 51, 247-257.

Merton, Robert C., 1971, "Optimum Consumption and Portfolio Rules in a ContinuousTime Model", Journal of Economic Theory 3, 373-413.

Merton, Robert C., 1973, "An Intertemporal Capital Asset Pricing Model", Econometrica $41,867-87$.

Merton, Robert C., 1990, Continuous Time Finance, Basil Blackwell, Cambridge, MA.

Samuelson, Paul A., 1969, "Lifetime Portfolio Selection by Dynamic Stochastic Programming", Review of Economics and Statistics 51, 239-246.

Schroder, Mark and Costis Skiadas, 1999, "Optimal Consumption and Portfolio Selection with Stochastic Differential Utility", Journal of Economic Theory 89, $68-126$. 
Tauchen, George and Robert Hussey, 1991, "Quadrature-Based Methods for Obtaining Approximate Solutions to Nonlinear Asset Pricing Models", Econometrica $59,371-396$.

Wachter, Jessica, 1999, "Portfolio and Consumption Decisions Under Mean-Reverting Returns: An Exact Solution for Complete Markets", unpublished paper, Harvard University.

Weil, Philippe, 1990, "Non-Expected Utility in Macroeconomics", Quarterly Journal of Economics 105, 29-42. 


\section{TABLE 1}

Estimates of the Stochastic Process

for Returns (1947.1 - 1995.4)

\section{(A) Restricted VAR(1):}

$$
\begin{aligned}
& \left(\begin{array}{c}
r_{1, t+1}-r_{f} \\
d_{t+1}-p_{t+1}
\end{array}\right)=\left(\begin{array}{c}
0.173 \\
(0.066) \\
-0.146 \\
(0.073)
\end{array}\right)+\left(\begin{array}{c}
0.047 \\
(0.020) \\
0.957 \\
(0.022)
\end{array}\right)\left(d_{t}-p_{t}\right)+\left(\begin{array}{l}
\epsilon_{1, t+1} \\
\epsilon_{2, t+1}
\end{array}\right) \\
& \Omega=\left(\begin{array}{cc}
5.296 E-3 & -4.290 E-3 \\
(0.540 E-3) & (0.522 E-3) \\
-4.290 E-3 & 6.397 E-3 \\
(0.522 E-3) & (0.653 E-3)
\end{array}\right) \quad R^{2}=\left(\begin{array}{c}
0.028 \\
0.910
\end{array}\right)
\end{aligned}
$$

(B) Derived Model:

$$
\begin{aligned}
& r_{1, t+1}-r_{f}=x_{t}+u_{t+1} \\
& x_{t+1}=\underset{(0.005)}{1.250 E-2}+\underset{(0.022)}{0.957}\left(x_{t}-\mu\right)+\eta_{t+1} \\
& \left(\begin{array}{cc}
\sigma_{u}^{2} & \sigma_{u, \eta} \\
\sigma_{u, \eta} & \sigma_{\eta}^{2}
\end{array}\right)=\left(\begin{array}{cc}
5.296 E-3 & -0.203 E-3 \\
(0.540 E-3) & (0.090 E-3) \\
-0.203 E-3 & 0.014 E-3 \\
(0.090 E-3) & (0.012 E-3)
\end{array}\right) \\
& r_{f}=.071 E-2 \quad \sigma_{x}^{2} / \sigma_{u}^{2}=3.215 E-2 \quad \operatorname{corr}(\eta, u)=-0.737
\end{aligned}
$$


TABLE 2

Mean Optimal Numerical Percentage Allocation to Stocks and Optimal Numerical (Log-Linear) Percentage Allocation to Stocks at the Mean of the State-Space

\begin{tabular}{|c|c|c|c|c|c|c|}
\hline \multirow[t]{2}{*}{ R.R.A. } & \multicolumn{6}{|c|}{ E.I.S. } \\
\hline & $1 / .75$ & 1.00 & $1 / 2$ & $1 / 4$ & $1 / 10$ & $1 / 20$ \\
\hline 1.00 & $\begin{array}{c}286.02 \\
286.02 \\
(286.02)\end{array}$ & $\begin{array}{c}286.02 \\
286.02 \\
(286.02)\end{array}$ & $\begin{array}{c}286.02 \\
286.02 \\
(286.02)\end{array}$ & $\begin{array}{c}286.02 \\
286.02 \\
(286.02)\end{array}$ & $\begin{array}{c}286.02 \\
286.02 \\
(286.02)\end{array}$ & $\begin{array}{c}286.02 \\
286.02 \\
(286.02)\end{array}$ \\
\hline 2.00 & $\begin{array}{c}199.81 \\
208.49 \\
(213.21)\end{array}$ & $\begin{array}{c}195.84 \\
204.04 \\
(208.64)\end{array}$ & $\begin{array}{c}189.58 \\
197.15 \\
(202.53)\end{array}$ & $\begin{array}{c}186.89 \\
194.15 \\
(199.78)\end{array}$ & $\begin{array}{c}185.27 \\
192.54 \\
(198.35)\end{array}$ & $\begin{array}{c}184.80 \\
192.03 \\
(197.86)\end{array}$ \\
\hline 4.00 & $\begin{array}{c}126.34 \\
130.14 \\
(133.08)\end{array}$ & $\begin{array}{c}125.76 \\
129.56 \\
(132.88)\end{array}$ & $\begin{array}{c}124.89 \\
128.75 \\
(132.58)\end{array}$ & $\begin{array}{c}124.48 \\
128.38 \\
(132.42)\end{array}$ & $\begin{array}{c}124.25 \\
128.18 \\
(132.33)\end{array}$ & $\begin{array}{c}124.17 \\
128.12 \\
(132.30)\end{array}$ \\
\hline 10.0 & $\begin{array}{c}57.38 \\
58.62 \\
(61.33)\end{array}$ & $\begin{array}{c}58.73 \\
60.00 \\
(63.11)\end{array}$ & $\begin{array}{c}61.16 \\
62.46 \\
(66.10)\end{array}$ & $\begin{array}{c}62.61 \\
63.92 \\
(67.73)\end{array}$ & $\begin{array}{c}63.58 \\
64.88 \\
(68.90)\end{array}$ & $\begin{array}{c}63.92 \\
65.22 \\
(69.27)\end{array}$ \\
\hline 20.0 & $\begin{array}{c}29.73 \\
30.39 \\
(32.18)\end{array}$ & $\begin{array}{c}30.84 \\
31.49 \\
(33.61)\end{array}$ & $\begin{array}{c}32.85 \\
33.49 \\
(36.06)\end{array}$ & $\begin{array}{c}34.06 \\
34.67 \\
(37.51)\end{array}$ & $\begin{array}{c}34.87 \\
35.46 \\
(38.42)\end{array}$ & $\begin{array}{c}35.15 \\
35.75 \\
(38.74)\end{array}$ \\
\hline
\end{tabular}

TABLE 3

Standard Deviation of the Optimal Numerical (Log-Linear) Percentage Allocation to Stocks

\begin{tabular}{|c|c|c|c|c|c|c|}
\hline \multirow[t]{2}{*}{ R.R.A. } & \multicolumn{6}{|c|}{ E.I.S. } \\
\hline & $1 / .75$ & 1.00 & $1 / 2$ & $1 / 4$ & $1 / 10$ & $1 / 20$ \\
\hline 1.00 & $\begin{array}{c}241.07 \\
(241.07)\end{array}$ & $\begin{array}{c}241.07 \\
(241.07)\end{array}$ & $\begin{array}{c}241.07 \\
(241.07)\end{array}$ & $\begin{array}{c}241.07 \\
(241.07)\end{array}$ & $\begin{array}{c}241.07 \\
(241.07)\end{array}$ & $\begin{array}{c}241.07 \\
(241.07)\end{array}$ \\
\hline 2.00 & $\begin{array}{c}137.26 \\
(151.24)\end{array}$ & $\begin{array}{c}135.59 \\
(150.01)\end{array}$ & $\begin{array}{c}132.05 \\
(148.27)\end{array}$ & $\begin{array}{c}130.55 \\
(147.45)\end{array}$ & $\begin{array}{c}129.49 \\
(147.02)\end{array}$ & $\begin{array}{c}129.24 \\
(146.87)\end{array}$ \\
\hline 4.00 & $\begin{array}{c}81.03 \\
(86.93)\end{array}$ & $\begin{array}{c}80.21 \\
(86.88)\end{array}$ & $\begin{array}{c}78.76 \\
(86.80)\end{array}$ & $\begin{array}{c}78.17 \\
(86.75)\end{array}$ & $\begin{array}{c}77.75 \\
(86.73)\end{array}$ & $\begin{array}{c}77.62 \\
(86.72)\end{array}$ \\
\hline 10.0 & $\begin{array}{c}35.21 \\
(38.21)\end{array}$ & $\begin{array}{c}35.31 \\
(38.70)\end{array}$ & $\begin{array}{c}35.55 \\
(39.50)\end{array}$ & $\begin{array}{c}35.73 \\
(39.93)\end{array}$ & $\begin{array}{c}35.86 \\
(40.22)\end{array}$ & $\begin{array}{c}35.92 \\
(40.32)\end{array}$ \\
\hline 20.0 & $\begin{array}{c}17.88 \\
(19.75)\end{array}$ & $\begin{array}{c}18.07 \\
(20.15)\end{array}$ & $\begin{array}{c}18.42 \\
(20.80)\end{array}$ & $\begin{array}{c}18.62 \\
(21.16)\end{array}$ & $\begin{array}{c}18.76 \\
(21.39)\end{array}$ & $\begin{array}{c}18.82 \\
(21.47)\end{array}$ \\
\hline
\end{tabular}


TABLE 4

Optimal Numerical (Log-Linear) Percentage

Consumption-Wealth Ratio at the Mean of the State-Space

\begin{tabular}{cccccccc}
\hline \multirow{2}{*}{ R.R.A. } & \multicolumn{7}{c}{ E.I.S. } \\
\cline { 3 - 7 } & & & & & & \\
\cline { 3 - 7 } & & $1 / .75$ & 1.00 & $1 / 2$ & $1 / 4$ & $1 / 10$ & $1 / 20$ \\
1.00 & 0.86 & 1.53 & 2.50 & 2.92 & 3.15 & 3.22 \\
& $(0.80)$ & $(1.53)$ & $(2.50)$ & $(2.93)$ & $(3.19)$ & $(3.27)$ \\
2.00 & 1.27 & 1.53 & 1.86 & 1.99 & 2.05 & 2.07 \\
& $(1.24)$ & $(1.53)$ & $(1.95)$ & $(2.15)$ & $(2.26)$ & $(2.30)$ \\
4.00 & 1.57 & 1.53 & 1.46 & 1.41 & 1.38 & 1.37 \\
& $(1.55)$ & $(1.53)$ & $(1.51)$ & $(1.50)$ & $(1.49)$ & $(1.49)$ \\
10.0 & 1.82 & 1.53 & 1.10 & 0.89 & 0.75 & 0.71 \\
& $(1.81)$ & $(1.53)$ & $(1.13)$ & $(0.92)$ & $(0.80)$ & $(0.75)$ \\
20.0 & 1.91 & 1.53 & 0.96 & 0.67 & 0.49 & 0.43 \\
& $(1.91)$ & $(1.53)$ & $(0.97)$ & $(0.69)$ & $(0.52)$ & $(0.46)$ \\
\hline
\end{tabular}

TABLE 5

Mean Optimal Numerical (Log-Linear)

Percentage Consumption-Wealth Ratio

\begin{tabular}{|c|c|c|c|c|c|c|}
\hline \multirow[t]{2}{*}{ R.R.A. } & \multicolumn{6}{|c|}{ E.I.S. } \\
\hline & $1 / .75$ & 1.00 & $1 / 2$ & $1 / 4$ & $1 / 10$ & $1 / 20$ \\
\hline 1.00 & $\begin{array}{c}0.84 \\
(0.78)\end{array}$ & $\begin{array}{c}1.53 \\
(1.53)\end{array}$ & $\begin{array}{c}2.74 \\
(2.80)\end{array}$ & $\begin{array}{c}3.34 \\
(3.56)\end{array}$ & $\begin{array}{c}3.70 \\
(4.07)\end{array}$ & $\begin{array}{c}3.82 \\
(4.25)\end{array}$ \\
\hline 2.00 & $\begin{array}{c}1.24 \\
(1.21)\end{array}$ & $\begin{array}{c}1.53 \\
(1.53)\end{array}$ & $\begin{array}{c}1.98 \\
(2.10)\end{array}$ & $\begin{array}{c}2.19 \\
(2.43)\end{array}$ & $\begin{array}{c}2.31 \\
(2.65)\end{array}$ & $\begin{array}{c}2.35 \\
(2.30)\end{array}$ \\
\hline 4.00 & $\begin{array}{c}1.55 \\
(1.53)\end{array}$ & $\begin{array}{c}1.53 \\
(1.53)\end{array}$ & $\begin{array}{c}1.51 \\
(1.57)\end{array}$ & $\begin{array}{c}1.50 \\
(1.61)\end{array}$ & $\begin{array}{c}1.49 \\
(1.64)\end{array}$ & $\begin{array}{c}1.49 \\
(1.65)\end{array}$ \\
\hline 10.0 & $\begin{array}{c}1.80 \\
(1.79)\end{array}$ & $\begin{array}{c}1.53 \\
(1.53)\end{array}$ & $\begin{array}{c}1.12 \\
(1.15)\end{array}$ & $\begin{array}{c}0.91 \\
(0.95)\end{array}$ & $\begin{array}{c}0.78 \\
(0.83)\end{array}$ & $\begin{array}{c}0.73 \\
(0.79)\end{array}$ \\
\hline 20.0 & $\begin{array}{c}1.91 \\
(1.90)\end{array}$ & $\begin{array}{c}1.53 \\
(1.53)\end{array}$ & $\begin{array}{c}0.97 \\
(0.98)\end{array}$ & $\begin{array}{c}0.68 \\
(0.70)\end{array}$ & $\begin{array}{c}0.50 \\
(0.52)\end{array}$ & $\begin{array}{c}0.44 \\
(0.47)\end{array}$ \\
\hline
\end{tabular}


TABLE 6

Standard Deviation of the Optimal Numerical (Log-Linear) Percentage Consumption-Wealth Ratio

\begin{tabular}{cccccccc}
\hline \multirow{2}{*}{ R.R.A. } & \multicolumn{7}{c}{ E.I.S. } \\
\cline { 3 - 7 } & & $1 / .75$ & 1.00 & $1 / 2$ & $1 / 4$ & $1 / 10$ & $1 / 20$ \\
& & 0.17 & 0.00 & 0.82 & 1.41 & 1.79 & 1.92 \\
1.00 & $(0.17)$ & $(0.00)$ & $(1.03)$ & $(2.08)$ & $(2.97)$ & $(3.32)$ \\
& 0.17 & 0.00 & 0.43 & 0.71 & 0.89 & 0.96 \\
2.00 & $(0.18)$ & $(0.00)$ & $(0.53)$ & $(0.97)$ & $(1.31)$ & $(1.44)$ \\
& 0.13 & 0.00 & 0.22 & 0.34 & 0.41 & 0.44 \\
4.00 & $(0.14)$ & $(0.00)$ & $(0.25)$ & $(0.41)$ & $(0.52)$ & $(0.56)$ \\
& 0.07 & 0.00 & 0.08 & 0.10 & 0.11 & 0.11 \\
10.0 & $(0.07)$ & $(0.00)$ & $(0.09)$ & $(0.12)$ & $(0.13)$ & $(0.13)$ \\
& 0.04 & 0.00 & 0.04 & 0.04 & 0.04 & 0.04 \\
20.0 & $(0.04)$ & $(0.00)$ & $(0.04)$ & $(0.04)$ & $(0.04)$ & $(0.04)$ \\
\hline
\end{tabular}

TABLE 7

Percentage of Den Haan-Marcet Statistics in the Lower (Upper) 5\% Critical Tail

\begin{tabular}{cccccccc}
\hline \multirow{2}{*}{ R.R.A. } & \multicolumn{7}{c}{ E.I.S. } \\
\cline { 3 - 7 } & & $1 / .75$ & 1.00 & $1 / 2$ & $1 / 4$ & $1 / 10$ & $1 / 20$ \\
& & 5.85 & - & 5.25 & 5.20 & 4.55 & 5.20 \\
1.00 & $(2.95)$ & $(-)$ & $(5.35)$ & $(5.95)$ & $(6.25)$ & $(5.70)$ \\
& & 5.00 & 4.80 & 3.80 & 5.30 & 4.05 & 4.45 \\
2.00 & & $(7.55)$ & $(6.75)$ & $(7.05)$ & $(7.55)$ & $(7.65)$ & $(6.90)$ \\
& & & & & & \\
4.00 & & 4.35 & 2.65 & 4.10 & 4.25 & 4.00 \\
& $(6.90)$ & $(6.10)$ & $(8.10)$ & $(6.45)$ & $(6.30)$ & $(8.20)$ \\
10.0 & 2.45 & 4.00 & 2.75 & 2.40 & 2.25 & 2.15 \\
& $(6.40)$ & $(4.80)$ & $(7.20)$ & $(8.45)$ & $(7.80)$ & $(7.95)$ \\
20.0 & 2.90 & 5.45 & 2.05 & 2.15 & 2.20 & 2.90 \\
& $(5.80)$ & $(4.75)$ & $(7.40)$ & $(9.30)$ & $(9.00)$ & $(7.00)$ \\
\hline
\end{tabular}


TABLE 8

Constrained Portfolio Choice:

Mean Optimal Percentage Allocation to Stocks, Optimal Percentage Allocation to Stocks at the Mean of the State-Space and Standard Deviation of the Optimal Percentage Allocation to Stocks

\begin{tabular}{|c|c|c|c|c|c|c|}
\hline \multirow[t]{2}{*}{ R.R.A. } & \multicolumn{6}{|c|}{ E.I.S. } \\
\hline & $1 / .75$ & 1.00 & $1 / 2$ & $1 / 4$ & $1 / 10$ & $1 / 20$ \\
\hline 1.00 & $\begin{array}{c}84.41 \\
100.00 \\
(34.05)\end{array}$ & $\begin{array}{c}84.41 \\
100.00 \\
(34.03)\end{array}$ & $\begin{array}{c}84.42 \\
100.00 \\
(34.03)\end{array}$ & $\begin{array}{c}84.43 \\
100.00 \\
(34.03)\end{array}$ & $\begin{array}{c}84.43 \\
100.00 \\
(34.02)\end{array}$ & $\begin{array}{c}84.43 \\
100.00 \\
(34.02)\end{array}$ \\
\hline 2.00 & $\begin{array}{c}83.45 \\
100.00 \\
(33.00)\end{array}$ & $\begin{array}{c}83.54 \\
100.00 \\
(32.95)\end{array}$ & $\begin{array}{c}83.68 \\
100.00 \\
(32.86)\end{array}$ & $\begin{array}{c}83.72 \\
100.00 \\
(32.86)\end{array}$ & $\begin{array}{c}83.80 \\
100.00 \\
(32.79)\end{array}$ & $\begin{array}{c}83.82 \\
100.00 \\
(32.70)\end{array}$ \\
\hline 4.00 & $\begin{array}{c}77.87 \\
100.00 \\
(32.15)\end{array}$ & $\begin{array}{c}78.21 \\
100.00 \\
(31.70)\end{array}$ & $\begin{array}{c}78.76 \\
99.86 \\
(31.37)\end{array}$ & $\begin{array}{c}79.38 \\
99.27 \\
(30.76)\end{array}$ & $\begin{array}{c}79.45 \\
99.47 \\
(30.79)\end{array}$ & $\begin{array}{c}80.06 \\
99.36 \\
(29.60)\end{array}$ \\
\hline 10.0 & $\begin{array}{c}55.91 \\
55.21 \\
(29.88)\end{array}$ & $\begin{array}{c}56.80 \\
56.33 \\
(29.58)\end{array}$ & $\begin{array}{c}57.34 \\
57.54 \\
(30.88)\end{array}$ & $\begin{array}{c}60.08 \\
61.24 \\
(28.84)\end{array}$ & $\begin{array}{c}60.17 \\
60.92 \\
(29.52)\end{array}$ & $\begin{array}{c}60.44 \\
61.27 \\
(29.56)\end{array}$ \\
\hline 20.0 & $\begin{array}{c}30.69 \\
31.17 \\
(17.28)\end{array}$ & $\begin{array}{c}31.83 \\
32.35 \\
(17.51)\end{array}$ & $\begin{array}{c}33.93 \\
34.37 \\
(17.66)\end{array}$ & $\begin{array}{c}35.17 \\
35.55 \\
(17.77)\end{array}$ & $\begin{array}{c}36.04 \\
36.40 \\
(17.88)\end{array}$ & $\begin{array}{c}36.34 \\
36.69 \\
(17.93)\end{array}$ \\
\hline
\end{tabular}


TABLE 9

Constrained Portfolio Choice:

Mean Optimal Percentage Consumption-Wealth Ratio, Optimal Percentage Consumption-Wealth Ratio at the Mean of the State-Space and Standard Deviation of the Optimal Percentage Consumption-Wealth Ratio

\begin{tabular}{|c|c|c|c|c|c|c|}
\hline \multirow[t]{2}{*}{ R.R.A. } & \multicolumn{6}{|c|}{ E.I.S. } \\
\hline & $1 / .75$ & 1.00 & $1 / 2$ & $1 / 4$ & $1 / 10$ & $1 / 20$ \\
\hline 1.00 & $\begin{array}{c}1.56 \\
1.57 \\
(0.09)\end{array}$ & $\begin{array}{c}1.53 \\
1.53 \\
(0.00)\end{array}$ & $\begin{array}{c}1.50 \\
1.48 \\
(0.14)\end{array}$ & $\begin{array}{c}1.48 \\
1.45 \\
(0.21)\end{array}$ & $\begin{array}{c}1.47 \\
1.43 \\
(0.25)\end{array}$ & $\begin{array}{c}1.46 \\
1.42 \\
(0.26)\end{array}$ \\
\hline 2.00 & $\begin{array}{c}1.61 \\
1.61 \\
(0.09)\end{array}$ & $\begin{array}{c}1.53 \\
1.53 \\
(0.00)\end{array}$ & $\begin{array}{c}1.43 \\
1.41 \\
(0.13)\end{array}$ & $\begin{array}{c}1.37 \\
1.34 \\
(0.19)\end{array}$ & $\begin{array}{c}1.34 \\
1.30 \\
(0.23)\end{array}$ & $\begin{array}{c}1.33 \\
1.29 \\
(0.24)\end{array}$ \\
\hline 4.00 & $\begin{array}{c}1.67 \\
1.68 \\
(0.09)\end{array}$ & $\begin{array}{c}1.53 \\
1.53 \\
(0.00)\end{array}$ & $\begin{array}{c}1.32 \\
1.30 \\
(0.12)\end{array}$ & $\begin{array}{c}1.21 \\
1.19 \\
(0.17)\end{array}$ & $\begin{array}{c}1.15 \\
1.11 \\
(0.19)\end{array}$ & $\begin{array}{c}1.12 \\
1.09 \\
(0.20)\end{array}$ \\
\hline 10.0 & $\begin{array}{c}1.81 \\
1.82 \\
(0.07)\end{array}$ & $\begin{array}{c}1.53 \\
1.53 \\
(0.00)\end{array}$ & $\begin{array}{c}1.11 \\
1.09 \\
(0.08)\end{array}$ & $\begin{array}{c}0.89 \\
0.87 \\
(0.10)\end{array}$ & $\begin{array}{c}0.75 \\
0.73 \\
(0.10)\end{array}$ & $\begin{array}{c}0.71 \\
0.69 \\
(0.10)\end{array}$ \\
\hline 20.0 & $\begin{array}{c}1.91 \\
1.92 \\
(0.04)\end{array}$ & $\begin{array}{c}1.53 \\
1.53 \\
(0.00)\end{array}$ & $\begin{array}{c}0.96 \\
0.96 \\
(0.04)\end{array}$ & $\begin{array}{c}0.67 \\
0.66 \\
(0.04)\end{array}$ & $\begin{array}{c}0.49 \\
0.48 \\
(0.04)\end{array}$ & $\begin{array}{c}0.43 \\
0.42 \\
(0.04)\end{array}$ \\
\hline
\end{tabular}




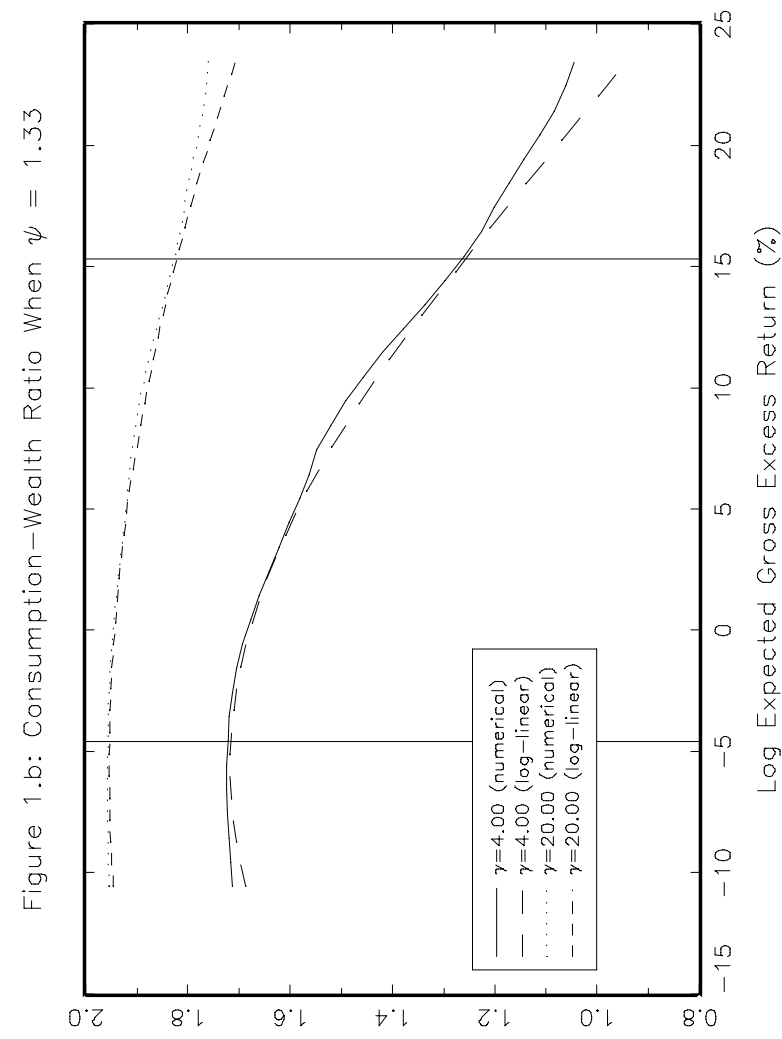

(\%) o!foy 47ן DaM-uo!fdunsuoJ

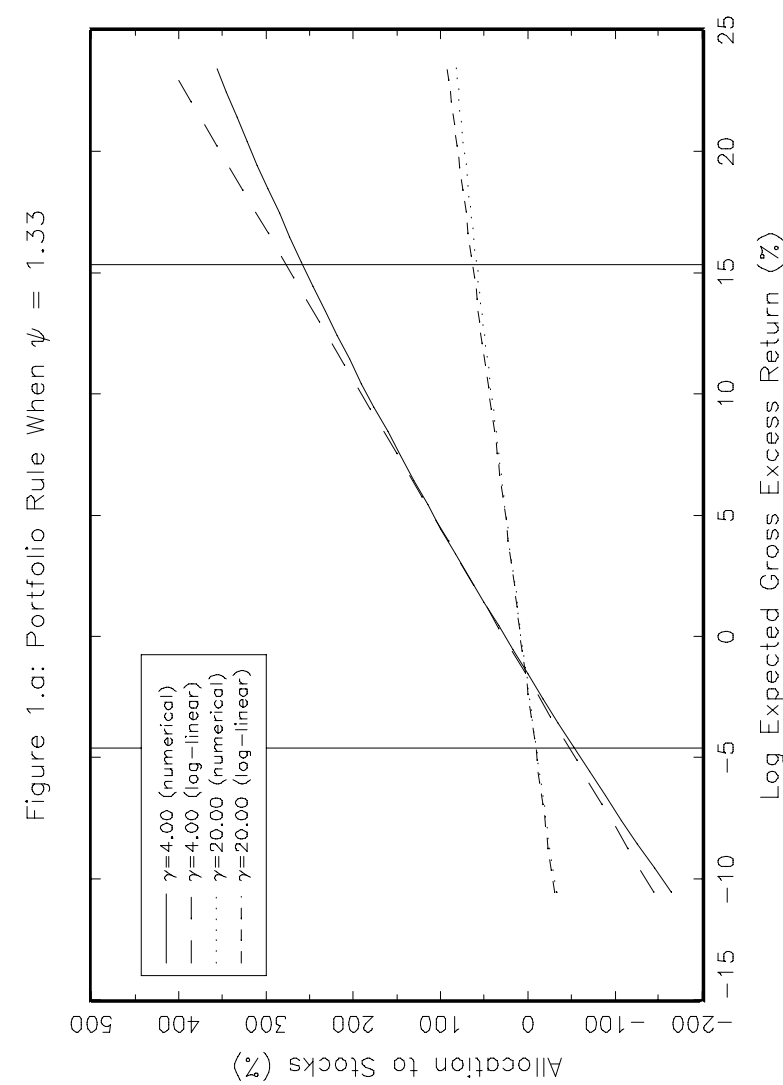

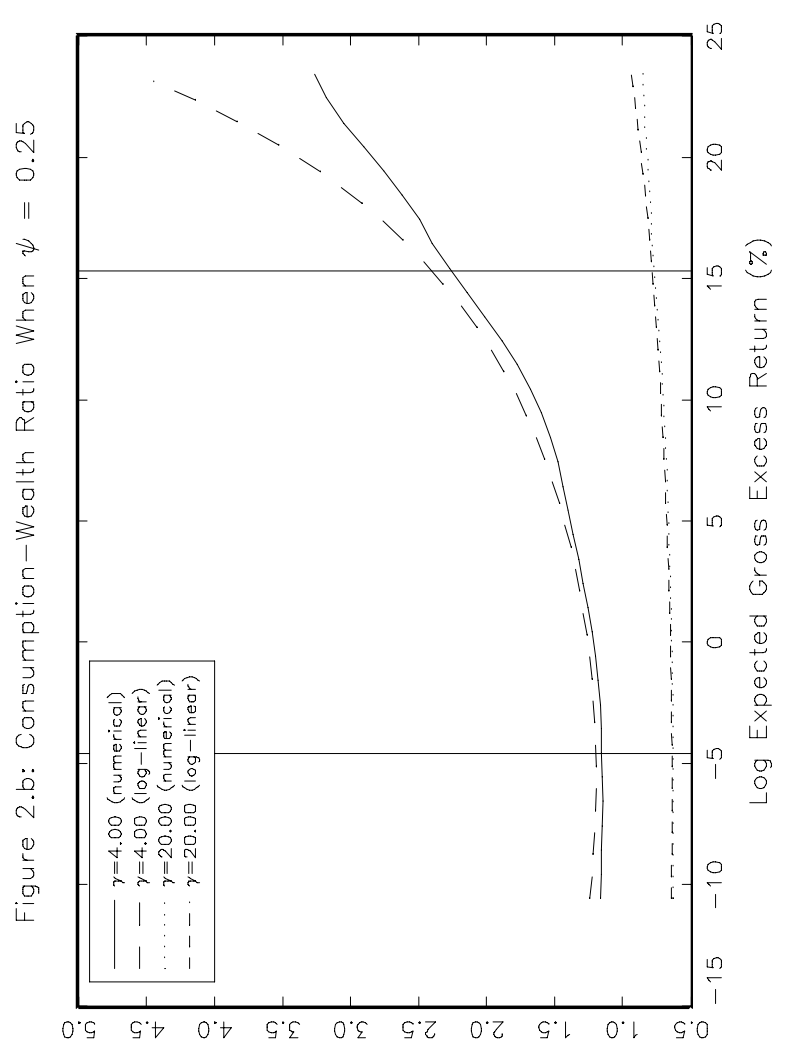

(\%) O!7Dy 47|DaM-uo!fdunsuoJ

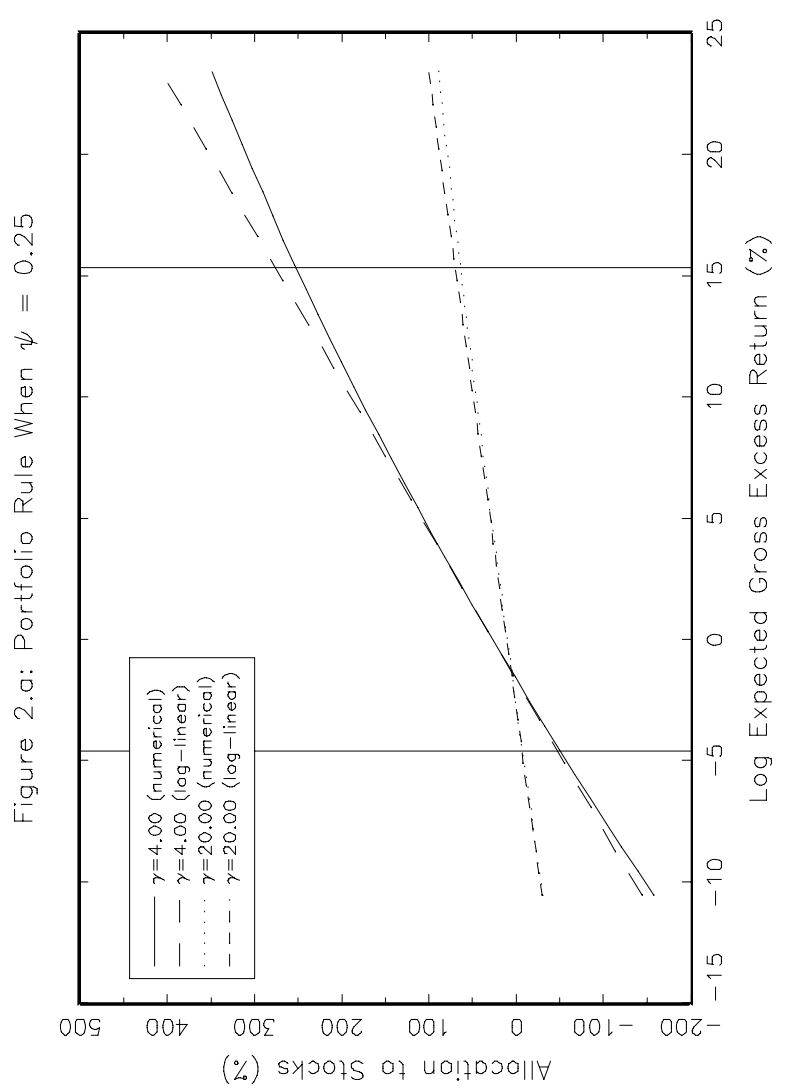



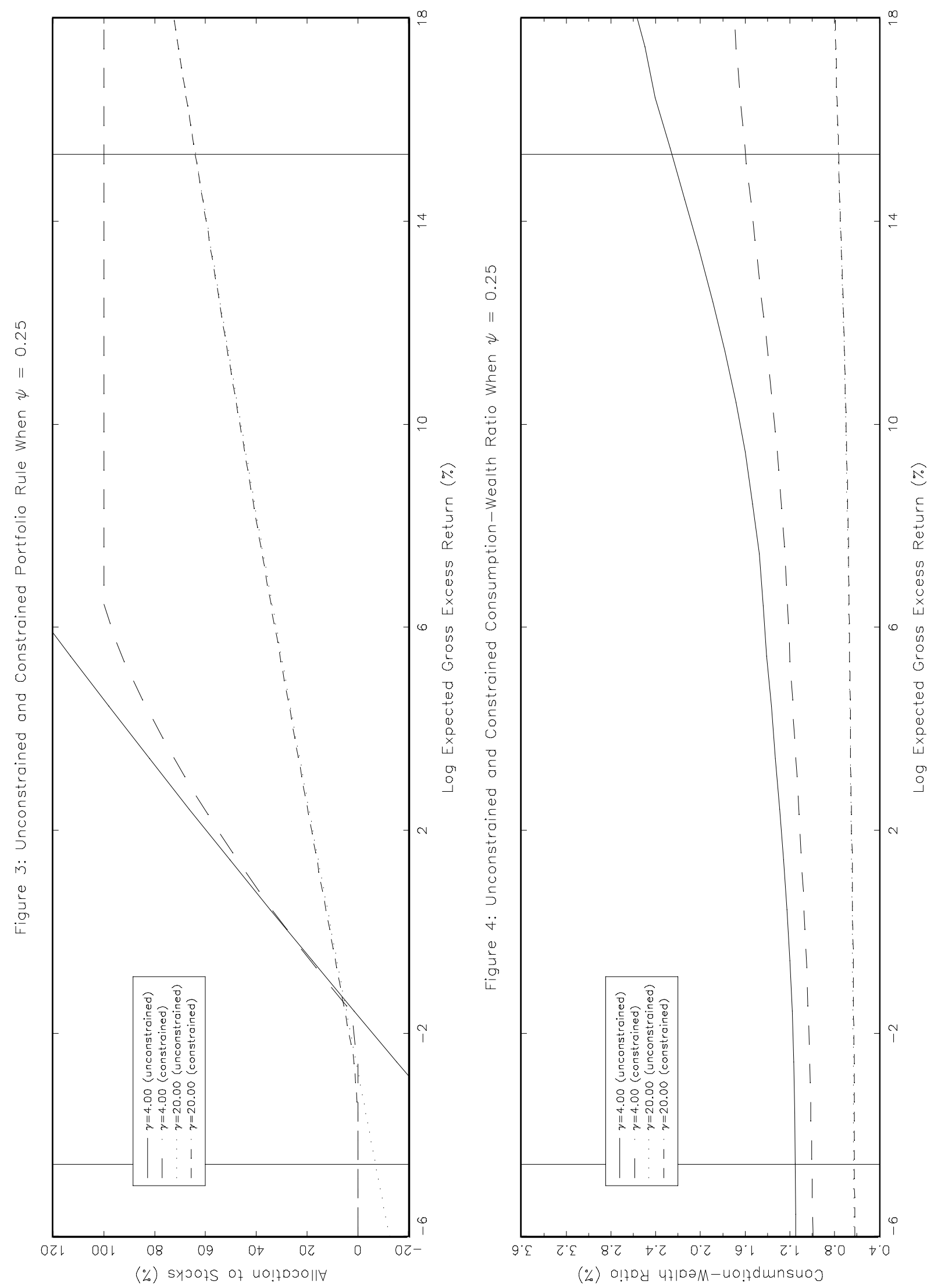